\title{
Ignacio Álvarez Rodríguez, Democracia equilibrada versus Democracia representativa, Congreso de los Diputados, Madrid, 2012
}

La obra del profesor Álvarez reflexiona sobre «las posibles aristas constitucionales que se observan respecto a determinadas medidas que intentan favorecer la presencia política de las mujeres en las principales instituciones representativas» (pág. 23), en concreto, la composición equilibrada de las listas electorales. Ciertamente, esta temática ha sido objeto de un número relativamente elevado de análisis en los últimos años. Sin embargo, en las próximas páginas se comprobará que dicha circunstancia no resta interés a un trabajo que, apoyado en una sólida estructura jurídico-constitucional, toma elementos de disciplinas análogas como la ciencia política, la sociología o la filosofía -«a veces, del Derecho» (pág. 24)- para convencernos de que la concepción paritaria introducida en nuestro ordenamiento no tiene un encaje sencillo en el dogma de la representación política presente en la Constitución de 1978.

En este sentido, el título que me propongo reseñar constituye un ejercicio sincero de análisis. El lector no tardará en comprobar la posición favorable del autor para con el impulso de la igualdad de género en el espacio político. Precisamente por ello, resulta destacable la respuesta ofrecida al final de la obra: «las disposiciones paritarias no casan del todo con algunos aspectos centrales sobre los que nuestra democracia representativa se basa», de manera que «quizás lo apropiado desde un punto de vista estrictamente jurídico sería operar una reforma constitucional» (pág. 211). Una afirmación rotunda que le obliga a desmontar la aparente nitidez de la jurisprudencia constitucional en la materia, sumiéndola en las sombras que proyectan las aristas a que hacía referencia al comienzo.

Apuntado el desenlace, es necesario aclarar algunos aspectos formales. La estructura del libro deja a las claras que su origen se encuentra en la tesis doctoral del autor. De esta forma, los cuatro capítulos que integran el estudio -Introducción y Conclusiones aparte- se ordenan en dos bloques temáticos diferenciados. El primero examina el aparato teórico propio de las acciones positivas y su operatividad en relación con las instituciones democráticas representativas. Por su parte, el segundo bloque se ocupa del empleo de estas técnicas en España, centrando su objeto en la reforma operada en la LOREG para la exigencia de la composición paritaria de las listas electorales.

La primera parte se inicia con la presentación del régimen jurídico de las acciones positivas. A pesar de lo extenso de la materia tratada, el autor ofrece un repaso muy significativo de esta doctrina, desde su aparición como elemento corrector de las discriminaciones étnicas en Estados Unidos, su progresiva inclusión en los principales instrumentos normativos internacionales y la recepción en la jurisprudencia constitucional española, en la que lamenta «que no se vislumbren unos criterios mínimos y coherentemente asentados 
para proceder al juicio de constitucionalidad de este tipo de disposiciones» de acción positiva (pág. 77).

Conocidos los medios que el ordenamiento jurídico pone a disposición del legislador, el siguiente capítulo se centra en su operatividad para conseguir dotar a la democracia vigente de un carácter paritario. Como no podía ser de otra forma, el primer hito del discurso pasa por identificar en qué consiste la paridad como rasgo adjetivo de la democracia. Desde esta perspectiva, el sugerente trabajo del autor pone a nuestra disposición los elementos de juicio necesarios: se trata de una idea reaccionaria al condicionamiento sexual inherente al contrato social, que bebe de la corriente igualitaria del feminismo más que de la revolucionaria, y que pretende operar un cambio en el sistema democrático que no se limite a aspectos meramente cuantitivos sino también cualitativos, de integración de la perspectiva de género en el debate político (pág. 85 y ss.). Así las cosas, la condición paritaria de la democracia excede de la corrección de la sobrerrepresentación masculina -representación descriptiva (pág. 92)-, operando como un elemento adicional de cambio social puesto que «la deliberación supone aceptar la posibilidad de modificar los intereses y posiciones iniciales, a través del intercambio racional de argumentos entre las partes, lo que permitiría a los representantes acoger y defender la causa femenina» (pág. 97).

Identificada la modalidad democrática que se pretende, resta valorar si el objetivo puede ser alcanzado mediante la implementación de medidas de acción positiva. A favor de tal conclusión parece decantarse la experiencia comparada. Ahora bien, la referencia debe tomarse en sentido abstracto, esto es, sobre la categoría, no sobre las medidas concretas a adoptar. Como apunta el autor, ni cabe realizar una tipología específica de las medidas de acción positiva posibles (págs. 99-100), ni la eficacia de éstas puede valorarse sin atender a otros factores exógenos como la cultura política y el sistema electoral vigente (pág. 108). Las medidas habrán de adaptarse a las circunstancias específicas del país.

Concluida la parte teórica, la segunda parte de la obra se dedica al estudio del impulso de la democracia paritaria en España. En el primero de los capítulos se analiza el origen y evolución de esta dinámica hasta la aprobación de la celebérrima Ley Orgánica 3/2007, para la igualdad efectiva de mujeres y hombres, por la que se introduce una «cuota bidireccional y neutra» (pág. 123) en relación con los cargos públicos representativos. Sin espacio para detenerse en este extremo, no puede pasarse por alto un -contundentecomentario relativo a la eficacia de esta medida para la mejor de la representación femenina en aquellos cargos: «cuando la realidad electoral española ha tenido que juzgar los rendimientos prácticos, las esperanzas depositadas en estas medidas se han enfriado» (pág. 138). Sin proponérselo, el autor lanza un aviso para navegantes: la promoción de la democracia paritaria podría haber errado no sólo en el vehículo normativo elegido, sino también en su redacción. 
Volviendo a los aspectos jurídico-constitucionales del objeto de estudio de la obra, el núcleo del trabajo lo conforma la presentación del escrutinio efectuado por el Tribunal Constitucional respecto de los -importantes- «puntos de fricción constitucional» que la reforma incluida por la ley de igualdad conoce (pág. 149). El recorrido realizado por el autor a través de la jurisprudencia resulta del máximo interés. Sin embargo, la finalidad pretendida no excede de la ofrenda al lector de los conocimientos precisos para el diálogo a tres bandas entre el juez constitucional, la doctrina y el propio autor con que se cierra el título y en el que afloran los puntos débiles de la argumentación manejada por el primero para avalar la constitucionalidad de la reforma.

De manera esquemática, la implementación de una medida como la señalada dentro del modelo de democracia definido en la Constitución de 1978 podría encontrar un primer problema de calado en el propio dogma de la representación parlamentaria. El profesor Álvarez Rodríguez se adhiere en este punto a la posición disidente del Magistrado Rodríguez-Zapata: la medida «interpone entre la soberanía y la categoría de ciudadano la condición sexual» (pág. 138). No podría ser de otro modo, pues la doctrina de la presencia -inherente al sistema de cuotas- «potencia la idea del reconocimiento identitario diferente, por lo que en este esquema los sujetos que llevan a cabo la representación importan, y mucho: deben pertenecer al colectivo en cuestión, para el caso que ahora se estudia: mujer-representa-mujer / hombrerepresenta-hombre» (pág. 172). Todo ello sin olvidar dificultades de carácter más concreto, como la posición jurídica del representante como vocero de la voluntad general (pág. 176) o el complejo encaje de la obligada presencia femenina en la autonomía de los grupos parlamentarios (pág. 179).

Más evidente pareciera la eventual contradicción entre el modelo de cuotas y el principio de igualdad en su vertiente de acceso a los cargos públicos representativos. Desde esta perspectiva, la postura del juez constitucional pasa por considerar la cuota de género un requisito adicional para el ejercicio de un derecho de configuración legal. Salvado el escollo, la aplicación indiferenciada de la exigencia a ambos sexos hace «harto difícil alegar una discriminación justamente fundada en tal característica» (pág. 136). Resulta discutible, empero, que una argumentación de este tipo pueda tener acomodo en un ámbito donde «rige el principio de favor libertatis» (pág. 188). Por este motivo el autor aboga por la introducción de una cláusula de apertura que no convierta el requisito del sexo en una causa de inelegibilidad que no solamente obedece a una lógica distinta a las ya existentes sino que "paradójicamente se convierte en un requisito que, de entrada, deja fuera la posibilidad de poner en marcha el mencionado sufragio» de manera abstracta, de modo que «desde el pistoletazo de salida, algunas mujeres y hombres quedarán imposibilitados a la hora de accionar su derecho a acceder al cargo como consecuencia de equilibrar las listas» (pág. 192).

Por último, la introducción del sistema de cuotas es valorada desde la perspectiva de los partidos políticos, pues «en el nacimiento y desarrollo 
de las formaciones partidarias confluyen, básicamente, el pluralismo político y las libertades asociativa e ideológica, sin perder de vista la relevancia en esta cuestión del derecho de sufragio» (pág. 193). Ya se ha aludido con anterioridad a la postura del autor sobre aspectos conexos a esta temática, a saber, la eficacia de las cuotas para la integración de la mujer o la fractura de la teoría de la representación política. Junto a los mismos, la libertad ideológica y de expresión de los partidos lleva a cuestionarse «si se podría estar abriendo una suerte de democracia neomilitante, que vendría a exigir una adhesión positiva de los partidos hacia determinadas formas de igualdad de género» (pág. 203). Éste es el punto donde más difieren las perspectivas del autor y el juez constitucional. El segundo niega cualquier avance en esta línea porque «los partidos podrán seguir defendiendo los principios políticos oportunos siempre que cumplan las exigencias que el ordenamiento impone» (pág. 136). Más dudas alberga el autor, para quien «conviene no olvidar que, de no cumplir con la (cuota), no se establece una sanción cualquiera, sino una de las más dolorosas, como es la no concurrencia a las elecciones correspondientes» (pág. 205). En otras palabras, se limita la libertad de acción y de organización de los partidos, obligándolos a llevar a cabo una conducta que no sólo se aleje de su ideología, sino que la contradiga (págs. 207-208).

Si se ha leído con atención todo lo expuesto, se coincidirá en la valoración positiva de esta obra. El lector avezado encontrará en la misma gran cantidad de información, un valioso resumen del estado de la cuestión y -principalmente- un cuidado análisis jurídico de la misma. Por su parte, el estilo claro y sencillo del discurso, unido a una muy estudiada cadencia, tanto en la presentación de los temas como en la introducción de perspectivas distintas de la estrictamente jurídica, contribuyen a que la lectura de la obra sea fácilmente asumible por los lectores menos expertos que deseen conocer más de una temática que, a pesar de su importancia capital, se ha visto envuelta en numerosos clichés a resultas de su proximidad a la esfera política.

Roberto Rosino Calle Centro Universitario de la Defensa en San Javier 